\title{
SWANSON'S SILASTIC IMPLANTS IN GREAT TOES
}

\author{
A. SETHU, D. C. D'NETTO, B. RAMAKRISHNA
}

From Tynemouth Victoria Jubilee Infirmary, North Shields

\begin{abstract}
This is a review of 77 partial replacement and interposition arthroplasties in which Silastic implants were used. The operations were carried out between 1971 and 1977 on the metatarsophalangeal joints of the great toes of 62 patients. Twenty-six of the operations were for painful hallux rigidus and 51 for hallux valgus. The patients were reviewed 12 to 92 months after operation, the average follow-up being 60 months.

The analysis of results indicated that while the procedure may be suitable for hallux rigidus its use for hallux valgus is not fully satisfactory in the long run.
\end{abstract}

Partial replacement and interposition arthroplasty with a Silastic implant was designed to meet some of the shortcomings of Keller's arthroplasty, the results of which are on the whole satisfactory but the patient is left with a short great toe, some lack of control of the digit and limitation of movement (Bonney and Macnab 1952; Thomas 1962). The procedure was expected to give a better appearance, improve control by maintaining length and help to preserve some mobility by providing a smooth articulating surface.

This follow-up study was undertaken to assess how far this expectation was fulfilled.

\section{MATERIALS AND METHODS}

Sixty-two patients out of a total of 90 on whom the operation was performed were traced and included in this study (Table I). Their ages ranged from 20 to 80 years but two-thirds were in their sixth or seventh decade. Among the 28 patients lost to follow-up, two had died, 15 patients moved away from the region and 11 failed to attend despite repeated requests. The prosthesis in all cases was the one designed by Swanson and manufactured by Dow Corning Corporation.

The operative technique was described by Swanson (1971). With the patient under general anaesthesia, the limb was exsanguinated and a pneumatic tourniquet applied. A curvilinear incision was made along the medial aspect of the tendon of the extensor hallucis longus. A distally based flap of capsule over the medial aspect of the metatarsophalangeal joint was elevated. The exostosis and the proximal third of the proximal phalanx were excised with a power saw. The medullary cavity of the proximal phalanx was reamed. A "trial" set was used to determine the appropriate size of prosthesis, which was then inserted and its stability tested through all ranges of movement. The elevated flap of capsule was anchored to the first metatarsal bone by a silk suture inserted through a hole drilled in its neck; this was to maintain the realignment of the great toe. The wound was closed in layers with Dexon sutures and a below-knee walking plaster was applied. The plaster cast was removed after six weeks and a course of physiotherapy was prescribed to develop the arches and intrinsic muscles of the foot and to regain any lost movement in the ankle, foot and great toe.

The duration of follow-up ranged from 12 to 92 months, the average being 60 months. To avoid discrepancies in observation, all the patients were seen by one author. Each patient was asked for his or her own opinion of the operation, the cosmetic result was noted and the range of movement in the joint recorded. The assessment also included the degree of residual deformity, recurrence of "bunion" or callosity, the presence or absence of metatarsalgia and a radiological examination.

The case records were analysed to show length of stay in hospital and complications, if any.

Table I. Details of 77 operations reviewed

\begin{tabular}{|c|r|r|c|c|c|c|}
\hline \multirow{2}{*}{ Diagnosis } & \multicolumn{3}{|c|}{ Side involved } & & \multicolumn{2}{c|}{$\begin{array}{c}\text { Number of } \\
\text { patients }\end{array}$} \\
\cline { 2 - 5 } & Right & Left & Bilateral & $\begin{array}{c}\text { Number of } \\
\text { operations }\end{array}$ & Men & Women \\
\hline Hallux valgus & 13 & 16 & 11 & 51 & 7 & 34 \\
Hallux rigidus & 7 & 11 & 4 & 26 & 11 & 10 \\
\hline
\end{tabular}

\section{ANALYSIS}

The average stay in hospital after operation was five days in unilateral replacement and 10 days in bilateral cases.

Complications. Five of the 77 toes developed superficial infection which resolved without any sequelae, but one developed a deep infection which necessitated removal of the prosthesis. Two patients showed radiological evidence of reaction in the bone adjacent to the implant; both had symptoms. The prosthesis had fragmented in one of them, but we do not know whether this was due to low-grade chronic infection or to rejection.

\section{Hallux rigidus}

In 21 ( 80 per cent) of the 26 cases of hallux rigidus the patients were free of any symptoms. Four patients admitted to a feeling of stiffness; one had pain, and

A. Sethu, FRCS, MS, Orthopaedic Registrar, Western Infirmary, Glasgow G11 6NT, Scotland.

D. C. D'Netto, FRCS, Consultant Orthopaedic Surgeon Tynemouth Victoria Jubilee Infirmary, Hawkey's Lane, North Shields,

B. Ramakrishna, FRCS, MS, Orthopaedic Department $\}$ Tyne and Wear NE29 0SF, England

Requests for reprints should be sent to Mr D. C. D'Netto. 


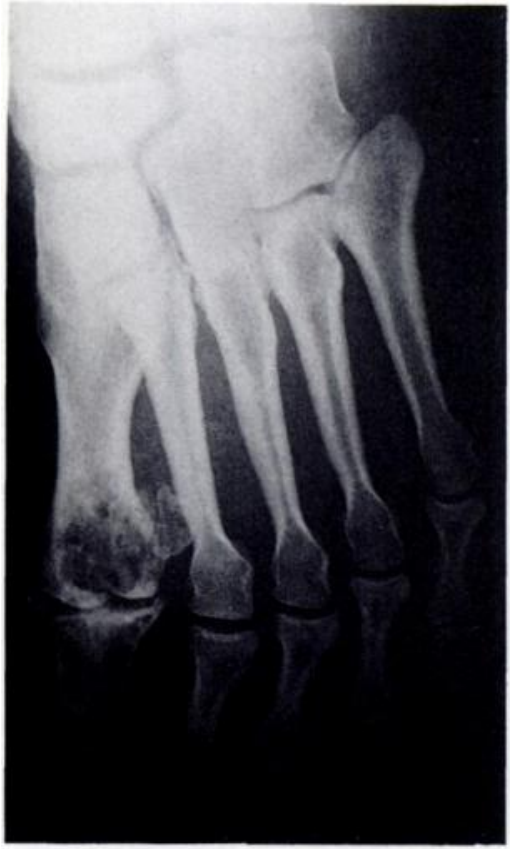

A. SETHU

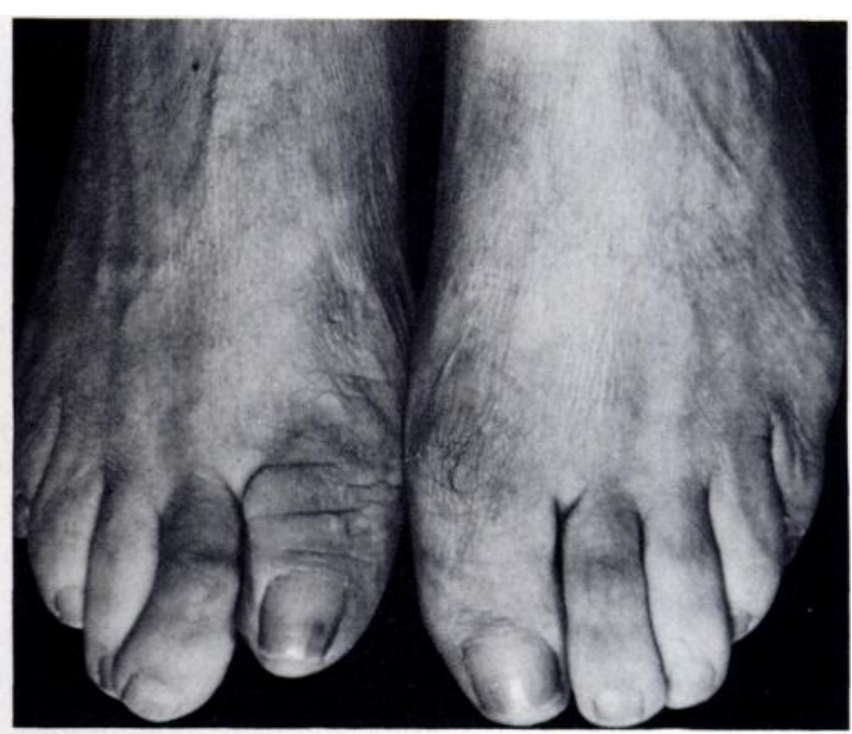

Fig. 2

A man aged 61 years who had a Keller's arthroplasty on the right great toe in 1961 and a Silastic partial replacement on the left great toe in 1974 had a better cosmetic result from the latter operation.

rise to complaints of either a recurrent bunion, deformity or metatarsalgia.

All the patients had some recurrence of valgus deformity, and although this was more than 20 degrees in 22 cases ( 44 per cent) (Table II; Figs 5 and 6) in none was it as severe as before operation. Most patients were

Table II. Recurrence of valgus deformity

\begin{tabular}{|l|l|c|}
\hline $\begin{array}{c}\text { Valgus deformity } \\
\text { (degrees) }\end{array}$ & Grade & $\begin{array}{c}\text { Number of } \\
\text { operations }\end{array}$ \\
\hline $0-10$ & Excellent & 15 \\
$11-20$ & Good & 14 \\
$21-30$ & Fair & 11 \\
$>30$ & Poor & 11 \\
\hline
\end{tabular}

satisfied because they had got rid of their bunions and could wear normal footwear; five, however, were prepared to have a further operation. Both bunion and callosity had recurred in 14 cases ( 28 per cent). Five patients still suffered from metatarsalgia.

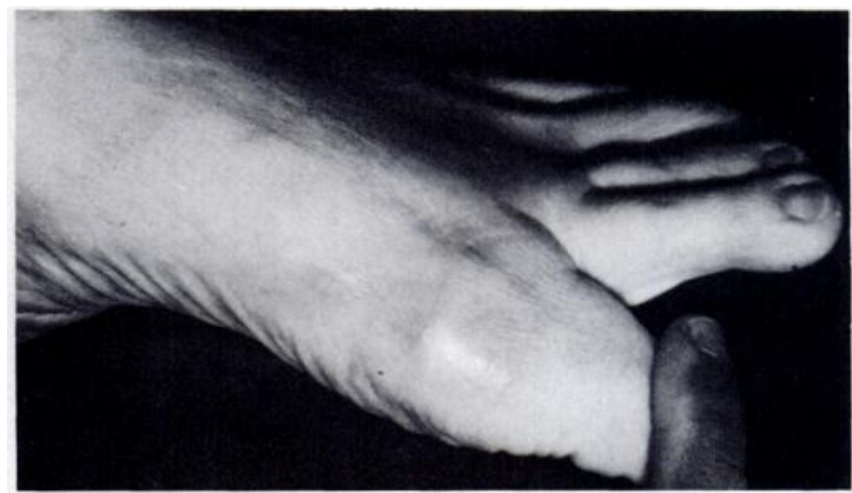

The range of movement in the great toe of a woman aged 47 years who had had a Silastic interposition arthroplasty for painful hallux rigidus six years previously. 
Using the same grading as before, the range of movement was considered excellent in 26 toes, good in 21 and poor in four (Figs 7, 8 and 9).

A mild degree of malrotation was noted in six cases (12 per cent) but only one patient complained that the nail of the great toe rubbed against the adjacent digit.

\section{DISCUSSION}

It is apparent that the results of the operation are different for hallux rigidus and hallux valgus.

Ninety-two per cent of the patients with hallux rigidus had a good result at review, and both cosmetically and functionally the operation had given an excellent result. We therefore continue to perform the operation on patients with hallux rigidus who wish to regain mobility of the joint.

All the patients with hallux valgus had some recurrence of the deformity which developed slowly. The prosthesis alone did not have the stability to withstand the forces producing the deformity. We therefore consider that for hallux valgus this procedure

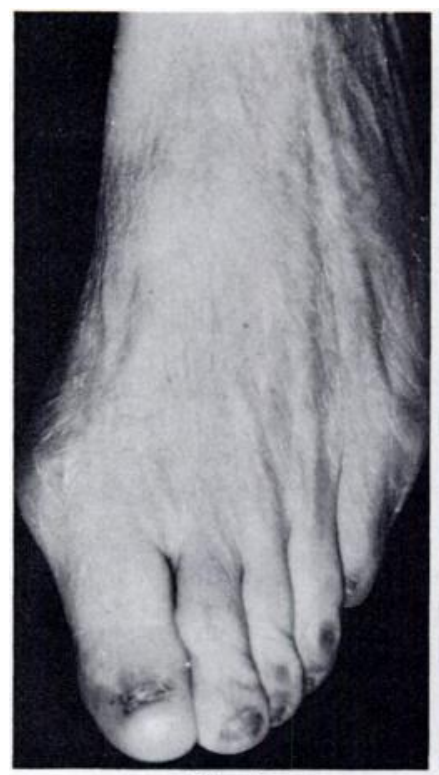

Fig. 5

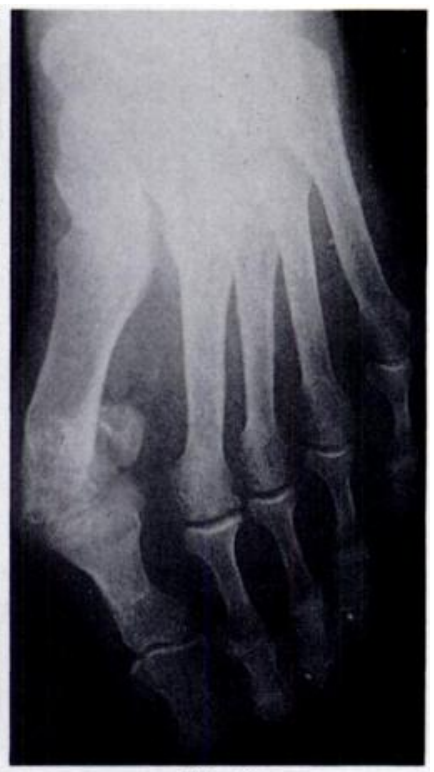

Fig. 6

Recurrence of deformity six and a half years after Silastic interposition arthroplasty for hallux valgus in a woman aged 68 years.

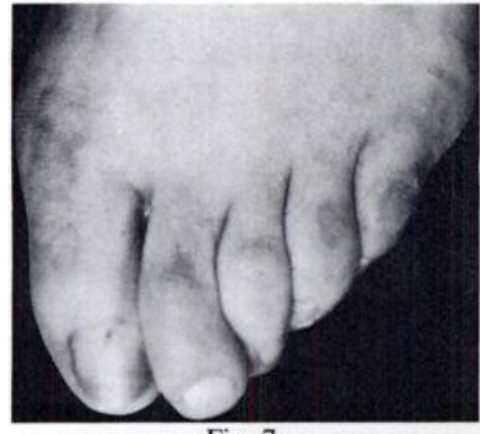

Fig. 7

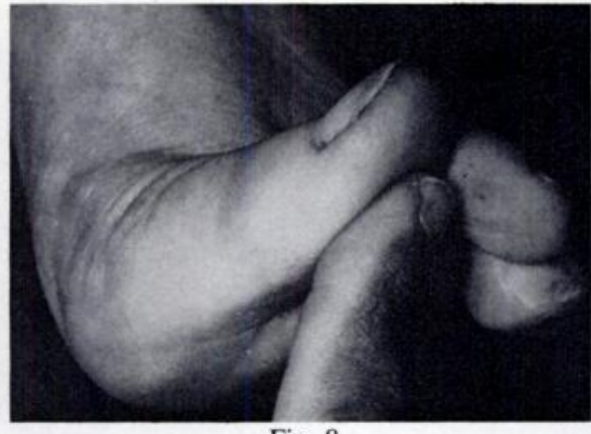

Fig. 8

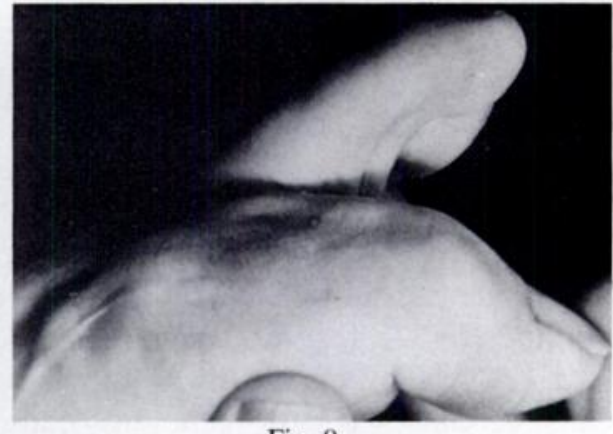

Fig. 9

The appearance and the range of movement of the great toe of a 59-year-old woman seven years after a Silastic interposition arthroplasty for hallux valgus.

would have to be supplemented by an osteotomy of the neck of the first metatarsal bone. Perhaps the new Silastic flexible-hinge implant, also designed by Swanson and manufactured by Dow Corning, with one of its stems inserted in the distal end of the first metatarsal, would be more resistant to muscle contraction and pressure of footwear thereby avoiding the need for any osteotomy.

\section{REFERENCES}

Bonney G, Macnab I. Hallux valgus and hallux rigidus. A critical survey of operative results. J Bone Joint Surg [Br] 1952;34-B:366-85. Swanson AB. Silastic great toe prosthesis. Dow Corning Bulletin 1971;Feb:51-040-01.

Thomas FB. Keller's arthroplasty modified. A technique to ensure post-operative distraction of the toe. J Bone Joint Surg [Br] 1962;44-B:356-65. 